\title{
PERSPECTIVAS
}

Artigo convidado

Versão original

DOI: http://dx.doi.org/10.1590/So034-759020180408

\section{AUTORES, PARECERISTAS E EDITORES: TRIPÉ DO PROCESSO DE REVISÃO DE ARTIGOS CIENTÍFICOS}

\section{INTRODUÇÃO}

Ao interagir com pessoas não tão próximas a mim ou que, apesar de próximas, não são ligadas ao meio acadêmico, frequentemente, escuto a seguinte pergunta: "Você não trabalha não? Só dá aula, é?". Embora os anos tenham me ensinado a responder com parcimônia a essa pergunta aparentemente acintosa - digo aparentemente, pois afinal ninguém é obrigado a saber os detalhes da profissão alheia - minhas réplicas e tréplicas tendem a não ser experiências agradáveis, seja pela dificuldade de me fazer compreender, seja pela expressão de fastio de meu interlocutor ao ouvir que parte significativa do tempo em que não estou dando aula é despendida com atividades de pouco glamour e de difícil abstração.

Via de regra, a conversa se encerra por ali mesmo. Porém, de quando em vez, a prosa se estende, quando menciono que, além de dar aulas da graduação ao doutorado, corrigir provas (socorro!), participar de bancas de trabalhos de conclusão e de concursos, pesquisar, escrever artigos para periódicos, que pouca gente lê, escrever artigos para imprensa, que um pouco mais de gente lê, orientar estudantes, realizar trabalhos administrativos (sou capaz de ouvir ao fundo uma voz gritando em inglês: boring...), prestar serviços à comunidade, atender à imprensa especializada, quando sou demandado, também faço pareceres de artigos científicos que podem afetar o destino de colegas de profissão no Brasil e no exterior.

Acredito que os acadêmicos que leem o relato acima já passaram por essa situação. Acredito, também, que parte significativa dos colegas que estão sujeitos às mesmas tarefas anteriormente descritas sente calafrios ao verificar pedidos de revisão de artigos pululando em suas caixas postais. Declinar de revisar o artigo ou aceitar a tarefa? Eis a questão. Podemos recusar, caso o artigo não tenha aderência a nossa área de conhecimento ou estejamos demasiadamente ocupados e não possamos fazer a revisão no prazo e na qualidade necessária. Nesses casos, em respeito a autores e editores, é melhor comunicar prontamente e não aceitar a tarefa. Sempre que possível, no entanto, devemos aceitar, principalmente se publicamos com frequência no periódico que nos 
qual uma mesa com três pés, problemas isolados numa ponta comprometem o equilíbrio do conjunto. A busca de um arranjo harmonioso requer, contudo, o entendimento das expectativas de cada uma das partes do tripé, para que se possa explorar as complementaridades existentes e garantir que aquilo que é publicado tenha rigor e relevância, gerando valor para a comunidade científica e para a sociedade de maneira mais ampla. Nesse sentido, a "pesquisa salame”, aquela que busca fatiar os achados em vários subprodutos para maximizar o número de publicações (Diniz, 2018), não se coaduna com essa perspectiva de valor e deve ser combatida por pareceristas e editores (gate keepers), no mínimo, como forma de se manter a credibilidade da comunidade.

Na sequência, discorro sobre as três perspectivas e, no final, tento conciliar as semelhanças, um pouco na linha do "foco no que nos une, não no que nos separa”. Espero que isso ajude a vislumbrar possíveis caminhos capazes de contornar os desafios que se apresentam no processo de revisão de artigos científicos na área de Administração no Brasil. Em alguns momentos, recorrerei ao uso da primeira pessoa do plural, por atuar como autor, parecerista e editor de periódicos científicos.

\section{OS AUTORES EM MEIO AO PROCESSO EDITORIAL}

Por mais que nos esmeremos em formatar uma contribuição acadêmica atrativa, capaz de informar algum aspecto ainda não explorado na literatura, de lançar luzes sobre determinados conceitos consolidados com diferentes perspectivas teóricas ou metodológicas, ou, ainda, com potencial de explicitar tensões existentes entre entendimentos conflitantes, ao fim e ao cabo, nosso objetivo é ver nossos artigos publicados, preferencialmente em veículos que são lidos e citados por nossos pares. Apesar de sabermos que nossa profissão envolve o julgamento de nossos trabalhos por pares especializados no tema, não raro, ficamos enfurecidos ao recebermos pareceres que não são de nosso agrado, sejam respostas negativas ou solicitações de revisões abordando pontos que entendemos como pouco relevantes.

Muito de nosso desapontamento vem pelo fato de atribuirmos a nós um valor maior do que realmente possuímos, conforme já decantado pela teoria de comparação social (Festinger, 1954). Parte disso tem origem também em nossa incapacidade, talvez imaturidade, de compreender a dinâmica do processo editorial e de nos colocarmos no lugar de editores, que nem sempre podem fazer as melhores escolhas de revisores, e de revisores que são pessoas como nós, ocupadas, com conhecimento limitado sobre determinados temas e que cometem alguns pecadinhos. Entre estes, a busca incessante pela perfeição alheia sem observar as próprias limitações. De fato, costumamos observar o cisco no olho de nossos interlocutores, sem nos darmos conta da trave em nossos olhos. Se muitas vezes agimos assim, por que esperar comportamento diferente dos outros? De igual sorte, muitas vezes, autores mais críticos pela demora em receber respostas para seus artigos são os mesmos que não respondem ao chamado dos editores de maneira responsiva, amiúde simplesmente ignorando os apelos.

Além do exercício de alteridade, para lidar com as frustrações inerentes à profissão, é recomendável outro exercício: o da autocrítica. Talvez seja prudente nos perguntarmos se nos esforçamos genuinamente na identificação de um problema de pesquisa relevante; se realmente realizamos uma varredura abrangente sobre o estado da arte da literatura naquele ponto que identificamos; se nossa teoria, no caso de pesquisa dedutiva, oferece hipóteses testáveis que representam avanços, e não o sumário de fenômenos óbvios e já esperados; e, por fim, se nossos dados e nossos métodos são suficientes e adequados para assegurar algum tipo de validade para nossos achados. Autores capazes de utilizar o produto dessa reflexão em seus artigos terão maiores chances de sobreviverem ao incerto processo de revisão por pares nos periódicos de sua escolha. Pareceres injustos e inúteis são frequentes e não cessarão, mas devem ser vistos como decorrência do processo de amadurecimento da academia, hoje certamente melhor do que há 10, 20 anos.

Nessa linha, o processo de revisão pode ser encarado como parte de nosso crescimento, pois, ainda que não tenhamos nosso suposto objetivo aceito, a oportunidade de aprendizado proporcionada pelo diálogo com pares tende a ser benéfica para todos os envolvidos, desde que haja o verdadeiro compromisso de gerar produções científicas efetivamente relevantes. Autores que não possuem a consciência de que produzir por produzir não é preciso e que optam pelo produtivismo de maneira deliberada (Cabral \& Lazzarini, 2011) não merecem o esforço abnegado de editores e revisores interessados em melhorar os níveis daquilo que é publicado.

\section{OS PARECERISTAS VISTOS EM PERSPECTIVA}

O processo de revisão por pares, embora amplamente aceito e consolidado, não é isento de críticas. Porém, ao que aparenta, o peer review, tal qual a democracia, parece ser o pior sistema depois de todos os outros (Miller, 2006). Em meio a esse 
processo imperfeito, pareceristas possuem um imenso poder sobre o desenvolvimento dos campos de conhecimento e sua própria vitalidade (Bedeian, 2003). Isso se dá, sobretudo, quando editores agem como meros intermediários e terceirizam as decisões editoriais, em teoria de sua responsabilidade, para os revisores. Tal distorção, diga-se de passagem, é algo relativamente corriqueiro em muitos dos periódicos da área de Administração no Brasil.

Diferentemente dos autores, referees podem ter múltiplas motivações, ao revisarem artigos científicos, além da contribuição abnegada para o progresso da ciência. Revisores em início de carreira ou iniciando interlocução numa nova área podem, por um lado, ser extremamente cuidadosos em seus pareceres, sendo construtivos para os autores e, ao mesmo tempo, bastante úteis no processo de decisão editorial. Em contrapartida, além da satisfação pelo dever cumprido, alavancam seu capital reputacional junto aos editores. Vassoura nova varre nos cantos. O lado negativo é que, por falta de experiência, excesso de zelo ou vontade demasiada em mostrar serviço, esse tipo de referee pode ser mais exigente do que o necessário e demandar modificações pouco relevantes ou até mesmo recomendar rejeição de artigos que poderiam evoluir durante interações sucessivas no processo de revisão. Editores que façam o cotejo entre os relatórios dos revisores e os manuscritos enviados pelos autores são fundamentais para reduzir a assimetria entre revisores e autores, de modo a evitar efeitos colaterais.

Um outro tipo de revisor pode ser bastante desagradável aos autores e potencialmente nocivo ao processo editorial: o parecerista ressentido, que, após ser tratado de maneira dura e, às vezes, desleal por outros pareceristas, procura compensar todo seu sofrimento passado sobre o trabalho do desafortunado autor que teve o privilégio de tê-lo como avaliador. Essa situação é similar à do irmão do meio que, ao apanhar do irmão mais velho, desconta no mais novo, que, em seu turno, desconta no cachorro. Há um lado de sadismo embutido nisso, é verdade, que não pode ser ignorado. Revisores que se vingam dos autores por não terem sido citados ou pelo fato de os artigos que avaliam colocarem em perspectiva seus próprios trabalhos anteriores também podem proporcionar experiências nada agradáveis aos autores. De igual sorte, autores padecem quando revisores conseguem identificar a autoria do trabalho e, para impedir o sucesso de desafetos ou de concorrentes (reais ou imaginários), colocam pedras adicionais no caminho. Nesses casos, cabe aos editores fazer a necessária arbitragem para o bem do processo editorial e para a sanidade de todos os envolvidos. De toda sorte, autores precisam saber lidar com esse processo, evitando chicanas com os referees e, sobretudo, realizando os esforços necessários para incluir aquilo que é pertinente e melhorar o artigo.
A conscientização dos pareceristas é fundamental para um processo de revisão construtivo. Antes de mais nada, é sempre bom lembrar que revisores são também autores e bem devem saber o quão frustrante é receber um parecer pouco construtivo após anos de trabalho a fio numa pesquisa. Revisores mais experientes não estão sujeitos à mesma estrutura de incentivos de pesquisadores mais jovens, tendem a estar envolvidos em outras funções e são, normalmente, aqueles que costumam declinar de revisar artigos em periódicos com maior frequência (Northcraft, 2001). Perdem autores, editores e a própria academia, que não se beneficia do conhecimento acumulado.

\section{EDITORES: GUARDIÃES DO PROCESSO EDITORIAL}

Ainda estudante de doutorado, tive a oportunidade de assistir a uma mesa-redonda com editores de periódicos, no ENANPAD de 2003 (Atibaia). Na ocasião, os editores dos poucos periódicos “A” da área de Administração expuseram as perspectivas e as agruras do ofício. Foi a primeira vez que vi a recorrente (e famigerada) figura que associa o processo editorial a um corredor polonês a ser cruzado pelo autor em meio a revisores com tacapes, pedaços de madeira com pregos e outros instrumentos de tortura. Ter um artigo aprovado seria uma decorrência da sobrevivência aos martírios experimentados durante o processo editorial. Aos olhos de quem estava fazendo uma tese de doutorado sobre o sistema prisional e já tinha lido Vigiar e punir de Foucalt, a figura fazia certo sentido e era emblemática. Lembro-me, também, da fala do então editor da RAE, Thomaz Wood, e de seu vaticínio sobre a função de editor: "Uma das maneiras mais eficazes para acumular inimigos". Talvez, as palavras não tenham sido exatamente essas, mas, após ter atuado com editor da O\&S e estar atuando como editor de número especial no Strategic Management Journal, comungo do diagnóstico sugerido por Thomaz, proferido na oportunidade à guisa de brincadeira, bem entendido.

De fato, em meio a um contexto em que o número de submissões é muito maior do que o número de espaço disponível para publicação, por uma questão de ordem simplesmente aritmética, editores de periódicos científicos, sob a ótica dos autores, tomam mais decisões negativas do que positivas. Considerando que as decisões negativas tendem a afetar a autoestima e a carreira de seus pares, a impopularidade de editores nos círculos acadêmicos não causa surpresa.

O processo decisório de editores de periódicos da área de Administração no Brasil ganha contornos adicionais de complexidade, em função da abrangência da área e de sua 
diversidade epistemológica, teórica e metodológica. Por mais que as boas revistas nacionais tenham montado estruturas de apoio baseadas em editores associados e em abnegados membros de seus conselhos editoriais para auxiliar no processo de seleção inicial (desk-review) e na escolha de pareceristas, o processo ainda está longe de controvérsia. Diferentemente de pares estrangeiros, que normalmente contam com redução em sua carga horária em sala de aula para exercer atividades editoriais, via de regra, editores de periódicos nacionais assumem tais tarefas sem nenhuma compensação. Em outras palavras, editores que trabalham arduamente no Brasil podem até gerar externalidades positivas, mas tendem a internalizar as externalidades negativas inerentes à atividade, seja na forma de novos inimigos, do descuido com sua própria agenda de pesquisa, da diminuição da qualidade de suas aulas ou, ainda, na redução de seu tempo dedicado aos entes queridos.

A dificuldade em selecionar bons referees, seja pela dificuldade de identificação, seja pela indisponibilidade de pesquisadores, que, embora recebam feedbacks em seus artigos como autores, hipocritamente, se recusam a atuar como pareceristas, faz com que não seja incomum que os artigos submetidos a periódicos (nacionais e internacionais) não sejam, na prática, avaliados por indivíduos com as melhores condições para julgá-los. Tais fatos contribuem para consolidar a impressão de que o destino de um artigo é determinado muito mais pelo resultado da alocação de pareceristas do que por sua qualidade intrínseca e seu potencial de contribuição para o progresso científico (Bedeian, 2003).

Editar um periódico científico altamente demandado é, em última instância, uma tarefa de gestão de recursos escassos, notadamente, pareceristas bons e disponíveis, os quais, no meu entender, são recursos valiosos, raros, de difícil imitação e que requerem uma organização adequada para que transformem seu potencial em valor superior, para utilizar um conceito da área de Estratégia (Barney, 1991). Proteger tais fontes de vantagem competitiva sustentável para um periódico é tarefa do editor. Para tanto, editores devem promover um rigoroso processo de desk-review, evitando enviar para bons e abnegados referees artigos com fragilidades intrínsecas e que terão poucas chances de sobreviver ao processo editorial ou, ainda, artigos com pouca aderência à área de domínio do revisor. Em ambos os casos, o tempo despendido (ou desperdiçado, como preferirem) do referee com tais artigos, além de ser uma alocação ineficiente de recursos, potencialmente implicará a indisponibilidade desse mesmo referee para avaliar outros artigos. Considerando que um revisor faz de uma a duas revisões por ano, que o número de artigos submetidos a revistas de ponta supera, em até 10 vezes, a capacidade de publicação e que, como já mencionado, bons pareceristas não surgem por geração espontânea, é essencial evitar cargas desnecessárias sobre esse recurso escasso.

Editores devem estar atentos à evolução do campo e às novas gerações de pesquisadores, cada vez mais bem treinados, registre-se. Bons alunos de doutorado e recémdoutores atualizados sobre o estado da arte da literatura, com domínio de métodos de pesquisa de ponta e ávidos para serem inseridos e ganharem legitimidade nos círculos acadêmicos, além de serem ótimas escolhas para compor o time de referees dos artigos, são fundamentais para a oxigenação e avanço do campo. Novas gerações pedem passagem, e é dever dos mais experientes treinar os noviços na função e abrir os caminhos para que tenhamos o aperfeiçoamento contínuo do processo de revisão de artigos científicos. Como diria Chico Buarque em Paratodos: "Evoé, jovens à vista”.

Além de proteger revisores de trabalhos ruins ou inadequados a seu perfil, editores devem valer-se de seu poder de gate keepers para proteger autores de revisores inadequados (ou rabugentos). Uma revisão injusta, mal-elaborada ou impertinente desmotiva autores e arranha a reputação do editor e de seu periódico. 0 desafio dos editores de periódicos da área de Administração consiste em promover esforços para mudar os padrões culturais existentes. Espera-se que, com isso, editores possam obter um maior número de pareceres informativos e rápidos que sejam capazes tanto de aconselhá-los na tomada de decisão quanto a guiarem os autores no processo de melhoria dos artigos.

\section{CONCILIANDO AS VISÕES E TOCANDO EM FRENTE}

Esta curta e, em certa medida, catártica reflexão não tem o interesse de esgotar o problema de revisão de artigos científicos da área de Administração ou de apontar fórmulas prontas para resolver os problemas. A complexidade do tema e os limites de espaço não permitem algo definitivo, por suposto. Do que foi abordado acima, no entanto, fica claro que os desafios inerentes ao processo de revisão podem ser enfrentados em algumas frentes.

Partindo-se da premissa de que sem esforço não há resultado, autores podem observar o estilo das publicações de referência em sua área, encontrar lacunas relevantes e passíveis de serem preenchidas por meio de sólidas construções teóricas e rigorosos métodos de investigação, caso a pesquisa seja de natureza aplicada. Revisores, mola mestra do processo de revisão, 
prestam grandes serviços à comunidade científica quando se dedicam à tarefa de escrutinar, com a devida honestidade intelectual, o trabalho de seus pares, contemplando rigidez nos critérios com gentileza e capacidade de guiar os autores na melhoria de seus trabalhos. Em seu turno, editores que efetivamente leem o material que é enviado a sua revista, que criam redes de assessoramento formais e informais para tomada de decisão e que protegem seus recursos escassos, bons pareceristas, são de grande valia para que o processo de avaliação por pares na área de Administração evolua e gere benefícios à comunidade. 0 constante exercício de se colocar no lugar dos demais envolvidos ao agir parece ser um bom caminho nesse sentido.

\section{AGRADECIMENTOS}

Agradeço a Marcio Machado e a Rafael Alcadipani pelos comentários e sugestões. Erros e omissões são de reponsabilidade do autor.

\section{REFERÊNCIAS}

Barney, J. B. (1991). Firm resources and sustained competitive advantage. Journal of Management, 17(1), 99-120. doi:10.1177/014920639101700108

Bedeian, A. G. (2003). The manuscript review process: The proper roles of authors, referees, and editors. Journal of Management Inquiry, 12(4), 331-338. doi:10.1177/1056492603258974

Cabral, S., \& Lazzarini, S. G. (2011). Internacionalizar é preciso, produzir por produzir não é preciso. Organizações \& Sociedade, 18(58), 541542. doi:10.1590/S1984-92302011000300011

Diniz, E. H. (2018). 0 gato que copia: Similaridades e produção acadêmica na era digital. RAE-Revista de Administração de Empresas, 58(2), 201-205. doi:10.1590/So034-759020180208

Festinger, L. (1954). A theory of social comparison processes. Human Relations, 7(2), 117-140. doi:10.1177/001872675400700202

Miller, C. C. (2006). Peer review in the organizational and management sciences: Prevalence and effects of reviewer hostility, bias, and dissensus. Academy of Management Journal, 49(3), 425-431. doi:10.5465/amj.2006.21794661

Northcraft, G. B. (2001). From the editors. Academy of Management Journal, 44(6), 1079-1080. doi:10.5465/amj.2001.18536870 